\title{
Effect of Temperature of Oxalic Acid on the Fabrication of Porous Anodic Alumina from Al-Mn Alloys
}

\author{
C. H. Voon, M. N. Derman, U. Hashim, K. R. Ahmad, and K. L. Foo \\ Institute of Nanoelectronic Engineering, Universiti Malaysia Perlis, Seriab, 01000 Kangar, Perlis, Malaysia \\ Correspondence should be addressed to C. H. Voon; david_voon@hotmail.com
}

Received 30 December 2012; Accepted 12 April 2013

Academic Editor: Lian Gao

Copyright ( 2013 C. H. Voon et al. This is an open access article distributed under the Creative Commons Attribution License, which permits unrestricted use, distribution, and reproduction in any medium, provided the original work is properly cited.

\begin{abstract}
The influence of temperature of oxalic acid on the formation of well-ordered porous anodic alumina on Al- $0.5 \mathrm{wt} \% \mathrm{Mn}$ alloys was studied. Porous anodic alumina has been produced on Al- $0.5 \mathrm{wt} \% \mathrm{Mn}$ substrate by single-step anodising at $50 \mathrm{~V}$ in $0.5 \mathrm{M}$ oxalic acid at temperature ranged from $5^{\circ} \mathrm{C}$ to $25^{\circ} \mathrm{C}$ for 60 minutes. The steady-state current density increased accordingly with the temperature of oxalic acid. Hexagonal pore arrangement was formed on porous anodic alumina that was formed in oxalic acid of 5,10 and $15^{\circ} \mathrm{C}$ while disordered porous anodic alumina was formed in oxalic acid of 20 and $25^{\circ} \mathrm{C}$. The temperature of oxalic acid did not affect the pore diameter and interpore distance of porous anodic alumina. Both rate of increase of thickness and oxide mass increased steadily with increasing temperature of oxalic acid, but the current efficiency decreased as the temperature of oxalic acid increased due to enhanced oxide dissolution from pore wall.
\end{abstract}

\section{Introduction}

Porous anodic alumina (PAA) is a self-organizing porous material. After the confirmation of the classical cell model proposed by Keller et al. [1], PAA has attracted enormous attraction as inexpensive template for the fabrication of various nanostructured materials without the need of costly and complex lithographic techniques [2-6]. PAA is a suitable template for the synthesis of nanostructured materials because its cell parameters such as pore diameter, interpore distance, and pore depth can be controlled easily by varying anodising conditions $[7,8]$. The fabrication of nanostructured materials by template synthesis method employs well-ordered PAA because well-ordered PAA provides regular pore shape and narrow distribution of specific pore diameter and interpore distance for the synthesis of nanostructured materials of uniform dimensions. Since the properties of nanostructured materials are significantly influenced by the dimensions, it is important to synthesize nanostructured materials of uniform dimensions $[6,9,10]$.

In order to fabricate well-ordered PAA, various approaches were proposed. First well-ordered PAA was realized by Masuda and Fukuda in 1995 [11]. They employ a two-step anodising method for the synthesis of wellordered PAA. Since then, owing to the commercial potential and scientific significance, there has been an ongoing research effort towards the fabrication of well-ordered PAA. Prepatterning methods such as imprint lithography [12-14], focused ion beam lithography [15], and electron beam lithography [16] were also developed for the fabrication of well-ordered PAA. These methods involved the formation of indented concave periodic patterns on the aluminium substrates prior to the anodising process. These patterns served as guide for the nucleation and growth of well-ordered PAA. Besides, high-field anodising was also proposed as an alternative for the synthesis of well-ordered PAA [17]. Critical high anodising potential which is the anodising potential required to induce high current density while preventing local current density concentration on the aluminium surface was applied during the high-field anodising.

Although many techniques for the synthesis of wellordered PAA were reported, these techniques employed high purity aluminium (99.99\%) substrate as a starting material. The cost of high purity aluminium is high and it has limited the commercial potential and applications of well-ordered PAA in the large-scale template synthesis of 
nanostructured materials. Therefore there is always a need to find an alternative of high purity aluminium substrate to widen the applications of PAA. Compared to high purity aluminium, the costs of aluminium alloys are relatively low. Thus, anodising of aluminium alloys is a good alternative to obtain low-cost template for the synthesis of nanostructured materials. However, due to the complexity of the anodising of aluminium alloys, there are only a few reports on the fabrication of PAA film from aluminium alloy, and most of these studies are emphasized on the commercially available aluminium alloys [18-21]. Commercially available aluminium alloys normally consist of $\mathrm{Si}, \mathrm{Fe}, \mathrm{Mg}, \mathrm{Mn}$, and $\mathrm{Cu}$ as alloying elements. These alloying elements have different behaviour during the anodising process. They may promote or hinder the fabrication of well-ordered PAA. Furthermore, these alloying elements may react among each other before or during the anodising process. The study of synthesis of PAA from commercially available aluminium alloy is therefore difficult to be analyzed and concluded.

Manganese $(\mathrm{Mn})$ is one of the major alloying elements used in aluminium alloys. It is added up to two percent to enhance the corrosion resistance of aluminium alloys, especially in 3xxx series. To the best of our knowledge, limited study was reported on the synthesis of PAA from Al-Mn alloys [22]. There is a growing interest in the development of economic alternative for the synthesis of well-ordered PAA. The cost of large-scale production of nanostructured materials can be significantly reduced when the well-ordered PAA is fabricated from aluminium alloys instead of expensive high purity aluminium. The synthesis of well-ordered PAA from Al-Mn alloys is affected by the anodising parameters such as temperature of oxalic acid. Thus, the purpose of this study is to investigate the effect of temperature of oxalic acid on the fabrication of well-ordered PAA on Al-Mn alloys. The results of this study are important in the optimization of anodising parameters for the fabrication of well-ordered PAA from Al-Mn alloys. In this context, we report a study of the effect of temperature of oxalic acid on the fabrication of wellordered PAA from Al-0.5 wt\% Mn alloys.

\section{Experimental}

To fabricate $\mathrm{Al}$ substrate of $0.5 \mathrm{wt} \% \mathrm{Mn}$ content, high purity (99.99\%) aluminium pellets and Al-20 wt $\%$ Mn master alloys of respective mass were melted at $850^{\circ} \mathrm{C}$. The molten mixture was then poured into a $25 \mathrm{~mm}$ diameter stainless steel cylindrical mould. Substrates of $4 \mathrm{~mm}$ in thickness were sectioned from casting product. To remove the residual stress on the substrates that was formed during the sectioning process, the substrates were annealed at $450^{\circ} \mathrm{C}$ for four hours and annealed in furnace to room temperature.

All substrates were ground by using silicon carbide paper up to 2000 grit to remove scratches formed on the substrate surfaces during sectioning process. The substrates were then polished by using alumina polishing suspension of $6 \mu \mathrm{m}$, $1 \mu \mathrm{m}$, and $0.05 \mu \mathrm{m}$ successively to achieve mirror-like surface. Substrates were degreased by dipping them in a stirred ethanol and rinsing them with deionised water. The mass of the substrates before being subjected to anodising were weighted and recorded.

Substrates were then anodised under the similar operating conditions except in oxalic acid of increasing temperature. Lead plate was used as cathode. The distance between the lead cathode and aluminium anode was $40 \mathrm{~mm}$. Anodising was performed at constant voltage for a sufficient time for the development of steady-state morphology within the film. Anodising was conducted at constant voltage of $50 \mathrm{~V}$ in $0.5 \mathrm{M}$ oxalic acid of $5^{\circ} \mathrm{C}, 10^{\circ} \mathrm{C}, 15^{\circ} \mathrm{C}, 20^{\circ} \mathrm{C}$, and $25^{\circ} \mathrm{C}$. The temperature variance was controlled within $\pm 0.5^{\circ} \mathrm{C}$. Current density-time curve was recorded during the anodising process. The anodised substrates were rinsed with flowing ethanol followed by deionised water and dried.

Three samples of $5 \mathrm{~mm} \times 5 \mathrm{~mm}$ in area each were sectioned from each anodised substrate. The cross-sections of the substrates were observed under SEM. The thickness of the PAA film was measured by using software JEOL SmileView version 2.1. The steady-state structure of PAA beneath the initially formed irregular structure was revealed by oxide dissolution treatment. A mixture of chromic acid and phosphoric acid was prepared from $20 \mathrm{~g}$ of chromium(VI) oxide and $35 \mathrm{~mL}$ of $85 \mathrm{wt} \%$ phosphoric acid in $1000 \mathrm{~mL}$ of distilled water. One anodised substrate of $5 \mathrm{~mm} \times 5 \mathrm{~mm}$ in area was then subjected to oxide dissolution treatment in a stirred mixture of chromic acid and phosphoric acid at $70-80^{\circ} \mathrm{C}$ for eight hours. The substrate was rinsed thoroughly with ethanol followed by distilled water and then dried. The morphology of the treated PAA was observed under SEM. Pore diameter and interpore distance of PAA were measured by using software JEOL SmileView version 2.1.

To measure the mass of oxide film formed, the same solution which was used for oxide dissolution treatment was prepared. The mass of the anodised substrates of $5 \mathrm{~mm} \times$ $5 \mathrm{~mm}$ in area before being subjected to dissolution process was recorded. The anodised substrate was then stirred in the mixture at $70-80^{\circ} \mathrm{C}$ for 8 hours. The substrate was rinsed thoroughly with ethanol and distilled water and then dried. The weight of the respective substrate was recorded. The difference between the weights of substrate before and after being subjeced to the oxide dissolution treatment is the mass of the PAA, $m_{p}$. The current efficiencies of the anodising of substrate of different Mn content were calculated based on the reported literature [23]. The mass of aluminium metal converted to oxide, $\left(m_{\mathrm{Al}}\right)_{\eta}$, was related to mass balance over the anodised sample in

$$
m_{p}=\left(m_{\mathrm{Al}}\right)_{\eta}+\left(m_{f}-m_{i}\right)
$$

in which $m_{i}$ and $m_{f}$ are the mass of the anodised sample before and after anodising, and these values were recorded previously. Current efficiency is defined as the ratio of the actual amount of current used for oxide formation relative to the total current passed. Mass of oxide formed, $m_{p}$, was determined from the difference between the masses of anodised sample before and after oxide dissolution. By fitting experimental values of $m_{p}, m_{f}$, and $m_{i}$ into $(1),\left(m_{\mathrm{Al}}\right)_{\eta}$ was 
determined. The mass of aluminium metal converted to oxide with current efficiency, $\eta=100 \%$ was determined by using

$$
\left(m_{\mathrm{Al}}\right)_{\eta}=\eta \frac{2 M_{\mathrm{Al}_{3}} A_{t} I t}{z F},
$$

in which $M_{\mathrm{Al}}$ is the molecular weight of aluminium alloy, $A_{t}$ is the anodised area, $I$ is the current density, $t$ is the anodising duration, $z$ is the number of electron involved in the reaction, $F$ is the Faraday constant, and $\left(m_{\mathrm{Al}}\right)_{\eta=100}$ is the mass of aluminium or aluminium alloy calculated using equation with current efficiency, $\eta=100 \%$. The current efficiency, $\eta$, was then determined by

$$
\eta=\frac{\left(m_{\mathrm{Al}}\right)_{\eta}}{\left(m_{\mathrm{Al}}\right)_{\eta=100}} .
$$

\section{Result and Discussion}

Figure 1 shows the effect of temperature of oxalic acid on the current density versus time transient for the anodising of Al- $0.5 \mathrm{wt} \% \mathrm{Mn}$ in $0.5 \mathrm{M}$ oxalic acid under the influence of $50 \mathrm{~V}$. The plots shared similar features and exhibited a typical manner of anodising of aluminium in oxalic acid [24]. At the commencement of anodising, there is a current surge. This current density surge is followed by a rapid fall in current density to a minimum. The current density then increases slowly to a steady-state value and remains at this value for the rest of the anodising time. At the initial stage, due to the low electrical resistance of the clean surface, the current density increases rapidly. When it reaches the peak, the thickening of nonconductive barrier type alumina occurs and the current density drops rapidly to a minimum value. However, the thickness of the barrier type alumina film is not uniform and pores exist on the surface of the film. The thickness of the alumina is lower at these pores and the electric field will concentrate at these pores. Field-assisted dissolution mechanism of the oxide film commences and the field electric resistance decreases with the emergence of the pores, and the current density increases subsequently. The steady-state current density is reached when the rate of oxide dissolution at the base of the pores equals the rate of oxide formation at the metal/oxide interface, indicating the finish of pore-organizing process [25].

It can be observed in Figures 1(a) and 1(b) that when the temperature of oxalic acid was raised from $5^{\circ} \mathrm{C}$ to $25^{\circ} \mathrm{C}$, the recorded current density rose generally. From Figure 1(a), the rate of current density decrease was not affected by the increasing temperature of oxalic acid. This indicated that the process of formation and growth of barrier layer was not affected by the change of temperature of electrolyte. However, the minimum current density and the rate of current density increase after pore nucleation increased when the temperature of oxalic acid increased although the time of occurrence of the minimum current density was essentially the same. The amplitude of reduction of current density decreased when the temperature of electrolyte increased. This indicated that the electrical resistance that was exerted by the PAA decreased with the increasing temperature of oxalic acid. This may be attributed to reduction of barrier layer thickness with the increased temperature of oxalic acid [25]. Furthermore, it was also observed that the rate of current density increases after pore nucleation increased with increasing temperature of oxalic acid. The steady-state current densities were also higher when the temperature of oxalic acid increased, as depicted in Figure 1(b). As the anodising was conducted at constant voltage of $50 \mathrm{~V}$, according to the Ohm's Law, the current density is inversely proportional to the electrical resistance exerted by the PAA. It suggested that the electrical resistance decreased as the temperature of electrolyte increased.

Except for anodising conducted in oxalic acid of $25^{\circ} \mathrm{C}$, when the steady-state current density was attained, there was no observed change to the current density, as depicted in Figure 1(b). This indicated that, for these conditions, there were no changes in the electrical resistance when the steadystate current density has been attained. The growth rate of PAA was stable for these conditions. This also indicated that the electrical resistance was mainly determined by the morphology and/or structure of PAA instead of the thickness of PAA. However, for anodising conducted in oxalic acid at $25^{\circ} \mathrm{C}$, the steady-state current density decreased with the extension of the anodising process. This was attributed to the high growth rate in the oxalic acid at this high temperature from the beginning of the oxidation. It was worth noting that there was a change in the electrolyte composition near the pore bottoms as a result of chemical reactions that occurred at the pore bottoms [26]. This included the reactions that were associated to the competing process of oxide formation and oxide dissolution. The change of electrolyte's composition depends on the growth rate of the PAA. Since the exchange of electrolyte species between the bulk of electrolyte and the electrolyte near the pore bottom was a diffusion-limited process, there was a concentration gradient of electrolyte species between the bulk electrolyte and the pore bottom [27]. The gradual reduction of the steady-state current density with the prolonged anodising was attributed to the accumulation and/or depletion of the electrolyte species.

The temperature of oxalic acid affects the movement of ions in the electrolyte and across the barrier layer, and the heat dissipation within the PAA during the anodising. Figure 2 shows the SEM images of PAA formed in oxalic acid of various temperatures. In general, the regularity of PAA deteriorated with the temperature of oxalic acid. For PAA formed at $5^{\circ} \mathrm{C}$ and $10^{\circ} \mathrm{C}$, a nearly perfect hexagonal pore arrangement of well-ordered PAA was observed in Figures 2(a) and 2(b), respectively. The pore diameter and interpore distance were uniform over the analysed surface area of these PAAs. The pores were circular in shape and no defect was observed in these analysed surface areas. As the temperature of the oxalic acid increased to $15^{\circ} \mathrm{C}$ in Figure 2(c), the hexagonal pore arrangement was still intact. However, the shapes of some of the pores were slightly deformed, as indicated by red circles in Figure 2(c). For anodising conducted in oxalic acid of $20^{\circ} \mathrm{C}$, as seen in Figure 2(d), no hexagonal arrangement was observed and the pores were deformed. The pore diameter and interpore distance of PAA formed in oxalic acid of $20^{\circ} \mathrm{C}$ varied greatly from one another. 


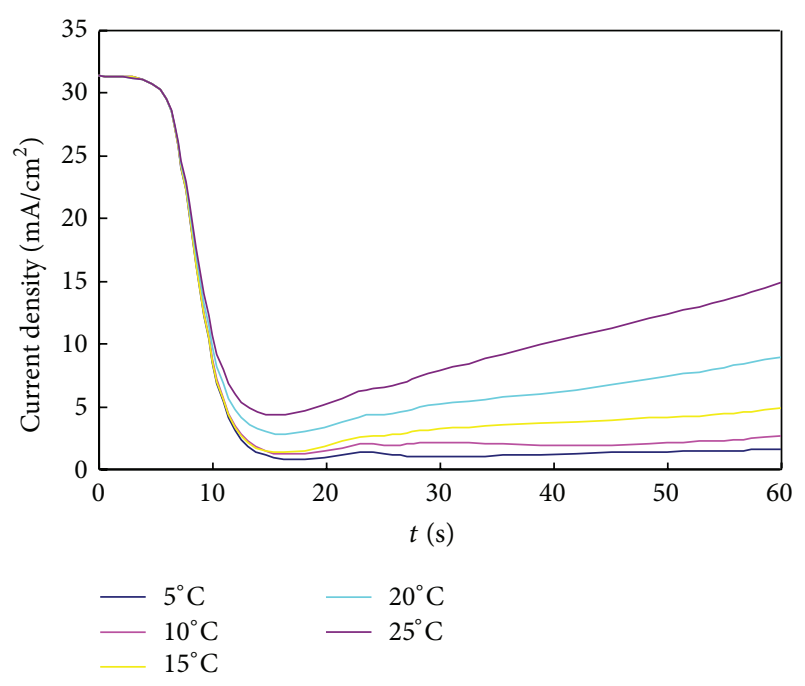

(a)

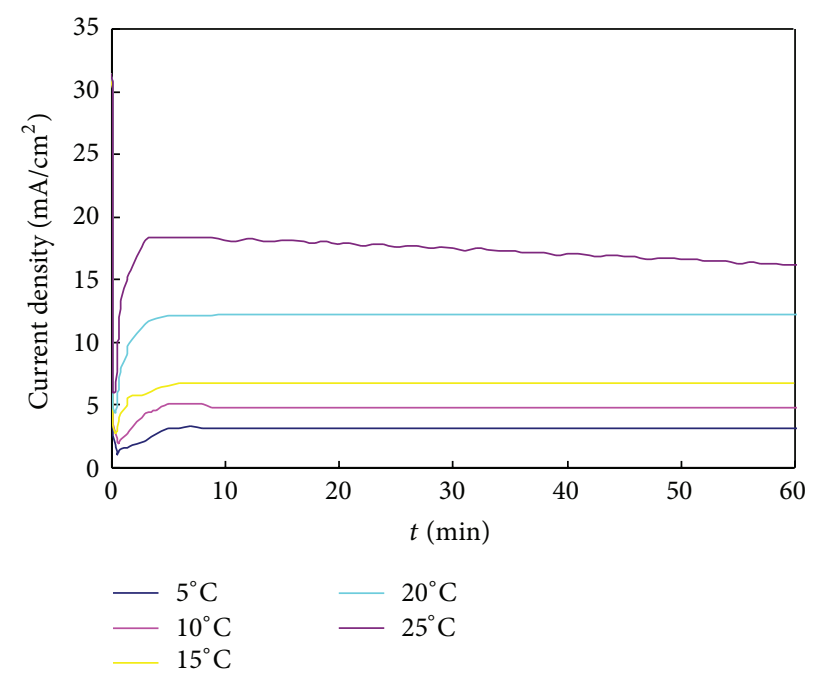

(b)

Figure 1: Current density versus time transient for the anodising of Al- $0.5 \mathrm{wt} \%$ substrates at $50 \mathrm{~V}$ in $0.5 \mathrm{M}$ oxalic acid of different temperatures up to (a) sixty seconds and (b) sixty minutes.

As the temperature of oxalic acid was further increased to $25^{\circ} \mathrm{C}$, a more inferior arrangement of pores was observed in Figure 2(e). Some of the pores were merged into a larger irregular pore, as indicated in red circle. As the temperature of oxalic acid was increased from $5^{\circ} \mathrm{C}$ to $25^{\circ} \mathrm{C}$, the rates of oxide dissolution at the oxide/electrolyte interface at pore base and rate of oxide formation at oxide/metal interface were increased. This was attributed to the reduction of barrier layer thickness with the increasing temperature of electrolyte [25]. At constant voltage of $50 \mathrm{~V}$, this led to strengthening electric field across the barrier layer at the pore base as a function of increasing temperature of oxalic acid. When anodising was conducted in oxalic acid of relatively low temperature, which was $5^{\circ} \mathrm{C}, 10^{\circ} \mathrm{C}$, and $15^{\circ} \mathrm{C}$ in this case, the growth rates of oxide were low and stable, as indicated by the low and constant steady-state current densities in Figure 1. This was due to the fact that the electric field across the barrier layer was relatively weak. This enabled a uniform formation of PAA and hexagonal pore arrangements were obtained. As the temperature of oxalic acid was increased to $20^{\circ} \mathrm{C}$ and $25^{\circ} \mathrm{C}$, the rates of oxide formation and dissolution were increased such that the local temperature increased. This subsequently led to enhanced heat dissipation and local stress. As a result, disordered pores arrangements were obtained in oxalic acid of $20^{\circ} \mathrm{C}$ and $25^{\circ} \mathrm{C}$. Similar observations were reported by Chowdhury et al. [28] in their study of effect of anodising parameters on the pore diameter and growth rates of PAA. Chowdhury et al. explained that this observation was attributed to the increase of dissolution rate at high temperature. This caused an increase to the local temperature at pore bottom which led to nonuniform pore distribution due to local stresses and increased heat dissipation.

In another study conducted by Hwang et al. [29], they investigated the effect of anodising voltage and temperature of oxalic acid on the synthesis of highly ordered PAA using high purity (99.999\%) aluminium, and they observed that at high temperature, which was $30^{\circ} \mathrm{C}$ in their study, no perfect hexagonal pore arrangement was observed. Hwang et al. [29] explained that larger extent of volume expansion during anodising in oxalic acid of high temperature was the reason for the formation of disordered pore arrangement. Furthermore, at high temperature, the rate of formation of oxide was very high such that the composition of electrolyte near the pore base was changed and diffusion-limited process occurred. This would also lead to disordered PAA.

The effect of temperature of $0.5 \mathrm{M}$ oxalic acid on the pore diameter and interpore distance of PAA formed at $50 \mathrm{~V}$ on $\mathrm{Al}-0.5 \mathrm{wt} \% \mathrm{Mn}$ substrates is shown in Figure 3. It can be seen that the temperature had little or no effect on both the pore diameter and interpore distance. It was different from previous study done by Sulka and Stepniowski [27] in which they studied the anodising of high purity aluminium at relatively high temperature. In their study, Sulka and Stepniowski found that significant differences in pore diameters were observed for anodising that was conducted at constant anodising potential in oxalic acid of various temperatures. They explained that the differences arose from the electrolyte chemical action along the cell walls that cause chemical dissolution of the oxide layer, considerably enhances with a prolonged anodising duration [27]. Thus, as the temperature of the oxalic acid increased, larger portion of alumina from the cell walls dissolved in the oxalic acid and led to enlargement of pore diameters at the surface of PAA. The dependence of pore diameter on the temperature of electrolyte was not observed in this study because, in this study, the SEM images were not taken from the surface of the PAA. Instead, the SEM images were taken after the PAA was subjected to oxide dissolution treatment. The pore diameter and interpore distance that 


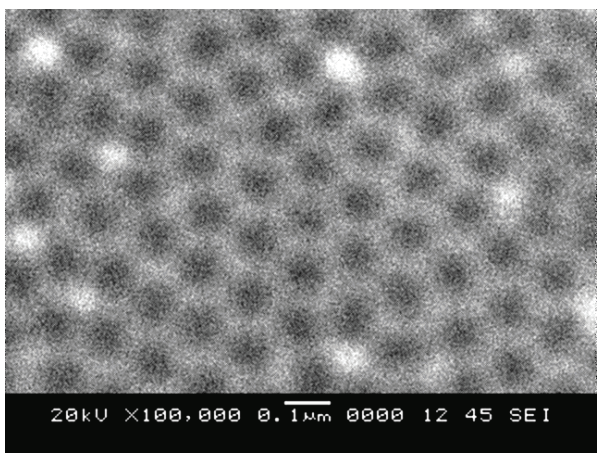

(a)

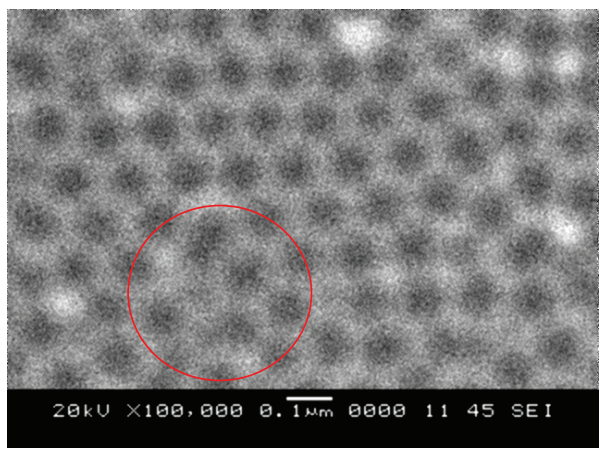

(c)

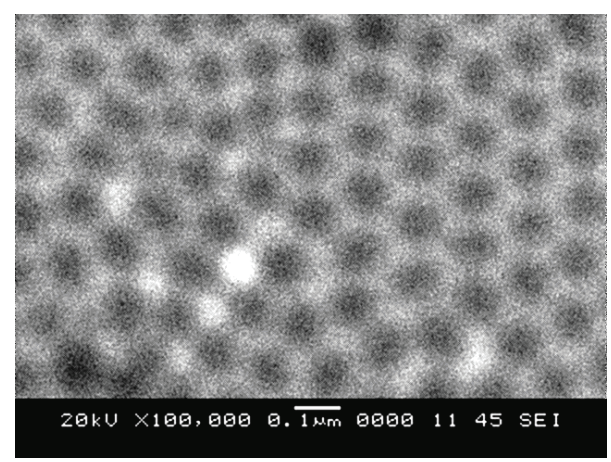

(b)

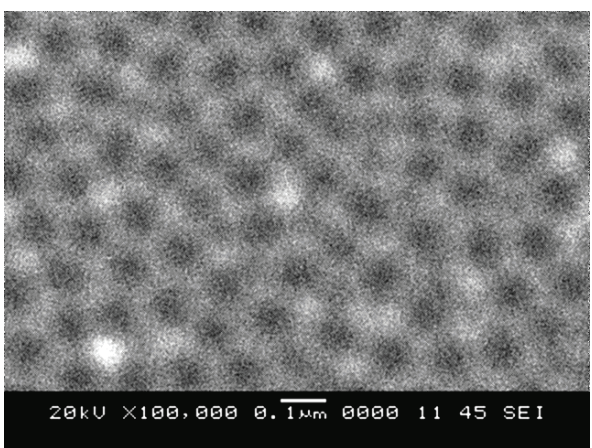

(d)

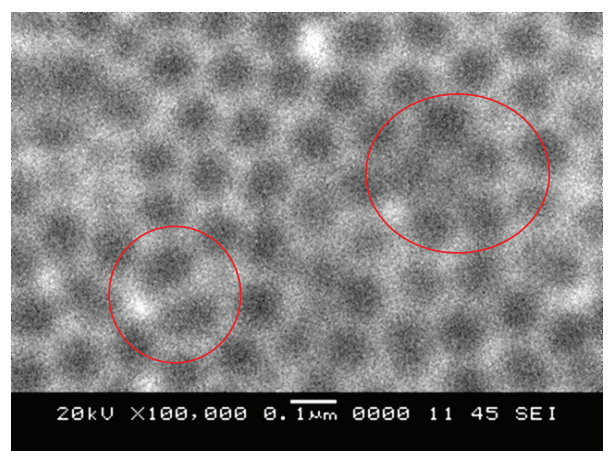

(e)

Figure 2: Top view SEM images of PAA anodised in $0.5 \mathrm{M}$ oxalic acid of (a) $5^{\circ} \mathrm{C}$, (b) $10^{\circ} \mathrm{C}$, (c) $15^{\circ} \mathrm{C}$, (d) $20^{\circ} \mathrm{C}$, and (e) $25^{\circ} \mathrm{C}$.

were measured were corresponded to steady-state growth of PAA. SEM images were not taken from the surface of the PAA because PAA at surface was initially formed and subjected to the chemical dissolution of the oxalic acid. Since the aggressiveness of oxalic acid increased with the temperature, at higher temperature, the chemical dissolution of alumina from the cell wall was more vigorous. This observation was supported by Aerts et al. [30] in their study of effect of anodising temperature on the properties of PAA. Aerts et al. found that, for all considered temperatures, the pore diameter increased from the pore base towards the oxide surface. The increment of pore diameter rose with the increasing anodising temperature leading to the formation of coneshaped pores. Aerts et al. explained that this phenomenon was attributed to the dissolving action of oxide by the electrolyte. Thus, pore diameter and interpore distance of PAA formed on Al- $0.5 \mathrm{wt} \% \mathrm{Mn}$ substrates under the influence of $50 \mathrm{~V}$ were not affected by the temperature of $0.5 \mathrm{M}$ oxalic acid that ranged from $5^{\circ} \mathrm{C}$ to $25^{\circ} \mathrm{C}$.

Thickness of PAA is an indication of the growth rate of the oxide film. It is important to control the thickness of the PAA to grow nanostructured materials of specific length. Figure 4 illustrates the effect of temperature of $0.5 \mathrm{M}$ oxalic acid on the thicknesses of PAA that were subjected to anodising voltage of $50 \mathrm{~V}$. It can be observed that, for a given duration of anodising process, the thickness of PAA increased significantly with increasing temperature of oxalic acid. This was in good agreement with the current density versus time transient in Figure 1, in which the steady-state current density increased with increasing temperature of oxalic acid. The enhanced electric field strength led to the increasing rate of formation of PAA and thus the thickness of PAA increased. 


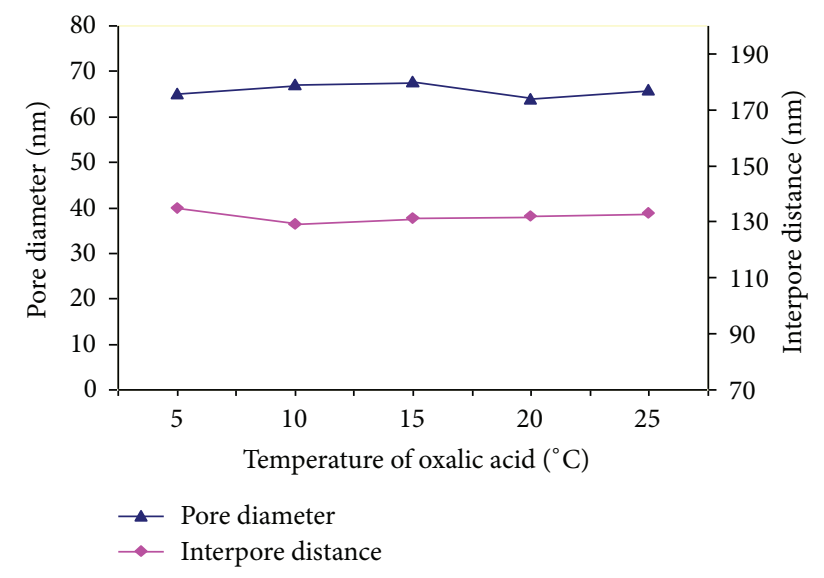

FIGURE 3: Variation of pore diameter and interpore distance of PAA as a function of temperature of oxalic acid.

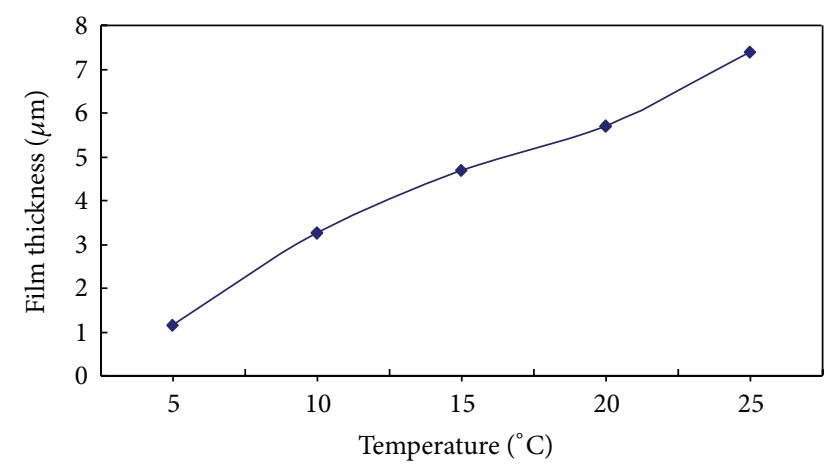

FIgURE 4: Thickness of PAA as a function of temperature of oxalic acid.

Hwang et al. [29] studied the effect of anodising voltage and temperature of oxalic acid on the formation of PAA on high purity aluminium. They observed that the growth rate of PAA increased when the temperature of oxalic acid increased from $5^{\circ} \mathrm{C}$ to $30^{\circ} \mathrm{C}$. They explained that this was due to fieldenhanced dissolution or temperature-enhanced dissolution.

Figure 5 illustrates the changes of current efficiency of anodising of Al- $0.5 \mathrm{wt} \% \mathrm{Mn}$ substrates that were conducted in $0.5 \mathrm{M}$ oxalic acid of temperatures range from $5^{\circ} \mathrm{C}$ to $25^{\circ} \mathrm{C}$. It can be seen that the current efficiency of the anodising process decreased significantly with the temperature of the oxalic acid. This was due to the enhanced aggressiveness of oxalic acid at higher temperature. Similar observation was reported by Ganley et al. [31] in their study of anodising of 1100 aluminium alloy in oxalic acid. Ganley et al. observed that the increasing temperature of electrolyte resulted in reduction of current efficiency for oxide formation through increasing the rate of aluminium oxide dissolution into the acidic electrolyte. This is due to the fact that thinner barrier layer was observed for PAA formed in electrolyte of higher temperature [25]. Reduction of thickness of barrier layer was resulted from the excessive dissolution of oxide into the electrolyte. The increasing porosity of PAA with the

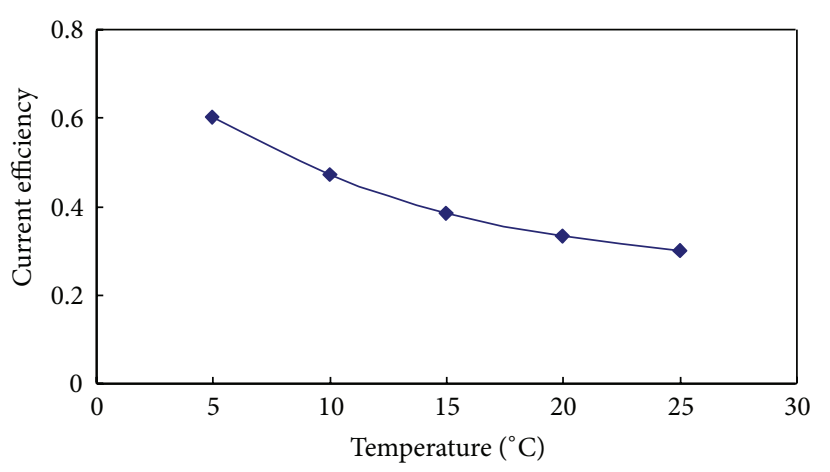

FIGURE 5: Current efficiency of anodising process as a function of temperature of oxalic acid.

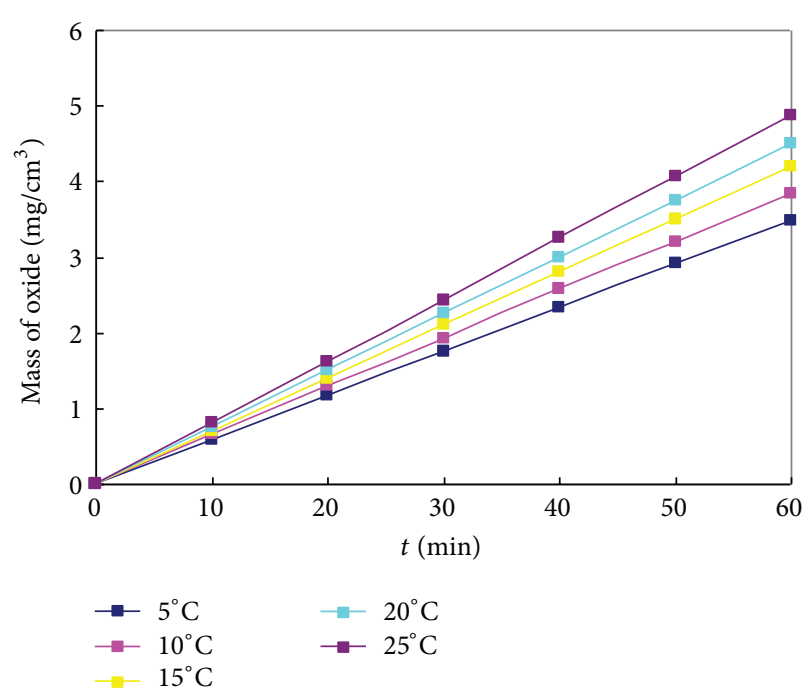

FIgURE 6: Oxide mass of PAA formed in oxalic acid of different temperature.

temperature of electrolyte was reported previously by Aerts et al. [30] in their study of effect of anodising temperature on the properties of PAA. The increasing porosity of PAA with the temperature of electrolyte supported the fact that the rate of oxide dissolution increased with the temperature of electrolyte and subsequently led to reduction of current efficiency.

Figure 6 exhibits the dependencies of mass of oxide formed on $\mathrm{Al}-0.5 \mathrm{wt} \% \mathrm{Mn}$ substrates at anodising voltage of $50 \mathrm{~V}$ on the temperature of oxalic acid of $0.5 \mathrm{M}$. As observed, the increasing temperature of oxalic acid increased the rate of oxide mass gain of PAA. This can be attributed to the increasing rate of formation of oxide in oxalic acid of higher temperature. Reduction of barrier layer with the increasing temperature of oxalic acid during potentiostatic anodising led to increasing electric field strength across the barrier layer. This subsequently led to increase rate of oxide formation (from $0.0583 \mathrm{mg} / \mathrm{min}$ to $0.08 \mathrm{mg} / \mathrm{min}$ ) with the increasing temperature of oxalic acid from $5^{\circ} \mathrm{C}$ to $25^{\circ} \mathrm{C}$. 


\section{Conclusion}

The temperature of oxalic acid affected the anodising behaviour and microstructure of PAA and the current efficiency of the anodising process. For the anodising conducted in oxalic acid of increasing temperature, the current density increased accordingly. When the anodising was carried in oxalic acid of $25^{\circ} \mathrm{C}$, the steady-state current density decreased gradually with time. Hexagonal pore arrangement was formed on PAA that was formed in oxalic acid of 5,10 , and $15^{\circ} \mathrm{C}$ while disordered PAA was formed in oxalic acid of 20 and $25^{\circ} \mathrm{C}$. Almost no effect on the pore diameter and interpore distance was detected when the temperature of oxalic acid was increased. Both rate of increase of thickness and oxide mass increased steadily with increasing temperature of oxalic acid, but the current efficiency decreased as the temperature of oxalic acid increased due to enhanced oxide dissolution from pore wall.

\section{Conflict of Interests}

All the authors have no financial arrangement with software JEOL SmileView offering financial support or grant monies, directly or indirectly, in regard to the study presented in this paper.

\section{References}

[1] F. Keller, M. S. Hunter, and D. L. Robinson, "Structural features of oxide coatings on aluminum," Journal of the Electrochemical Society, vol. 100, no. 9, pp. 411-419, 1953.

[2] C. C. Lin and C. L. Yang, "Carbon nanotubes grown on nanoporous alumina templates/aluminum foil for electrodes of aluminum electrolytic capacitors," Journal of the Electrochemical Society, vol. 157, no. 2, pp. A237-A241, 2010.

[3] Y. C. Sui, J. A. González-Leon, A. Bermúdez, and J. M. Saniger, "Synthesis of multi branched carbon nanotubes in porous anodic aluminum oxide template," Carbon, vol. 39, no. 11, pp. 1709-1715, 2001.

[4] Z. Chen, Y. Lei, H. G. Chew, L. W. Teo, W. K. Choi, and W. K. Chim, "Synthesis of germanium nanodots on silicon using an anodic alumina membrane mask," Journal of Crystal Growth, vol. 268, no. 3-4, pp. 560-563, 2004.

[5] L. Li, S. Pan, X. Dou et al., "Direct electrodeposition of $\mathrm{ZnO}$ nanotube arrays in anodic alumina membranes," Journal of Physical Chemistry C, vol. 111, no. 20, pp. 7288-7291, 2007.

[6] S.-H. Jeong, H.-Y. Hwang, S.-K. Hwang, and K.-H. Lee, "Carbon nanotubes based on anodic aluminum oxide nano-template," Carbon, vol. 42, no. 10, pp. 2073-2080, 2004.

[7] A. Belwalkar, E. Grasing, W. van Geertruyden, Z. Huang, and W. Z. Misiolek, "Effect of processing parameters on pore structure and thickness of anodic aluminum oxide (AAO) tubular membranes," Journal of Membrane Science, vol. 319, no. 1-2, pp. 192-198, 2008.

[8] S. Ono and N. Masuko, "Evaluation of pore diameter of anodic porous films formed on aluminum," Surface and Coatings Technology, vol. 169-170, pp. 139-142, 2003.

[9] X. Qu, J. Dai, J. Tian et al., "Syntheses of $\mathrm{Nd}_{2} \mathrm{O}_{3}$ nanowires through sol-gel process assisted with porous anodic aluminum oxide (AAO) template," Journal of Alloys and Compounds, vol. 469, no. 1-2, pp. 332-335, 2009.
[10] Y. Zhao, M. Chen, X. Liu, T. Xu, and W. Liu, "Electrochemical synthesis of polydiphenylamine nanofibrils through AAO template," Materials Chemistry and Physics, vol. 91, no. 2-3, pp. 518523, 2005.

[11] H. Masuda and K. Fukuda, "Ordered metal nanohole arrays made by a two-step replication of honeycomb structures of anodic alumina," Science, vol. 268, no. 5216, pp. 1466-1468, 1995.

[12] J. Choi, K. Nielsch, M. Reiche, R. B. Wehrspohn, and U. Gosele, "Fabrication of monodomain alumina pore arrays with an interpore distance smaller than the lattice constant of the imprint stamp," Journal of Vacuum Science \& Technology B, vol. 21, no. 2, pp. 763-766, 2003.

[13] N. Kwon, K. Kim, J. Heo, and I. Chung, "Fabrication of ordered anodic aluminum oxide with matrix arrays of pores using nanoimprint," Journal of Vacuum Science and Technology A, vol. 27, no. 4, pp. 803-807, 2009.

[14] H. Masuda, H. Asoh, M. Watanabe, K. Nishio, M. Nakao, and T. Tamamura, "Square and triangular nanohole array architectures in anodic alumina," Advanced Materials, vol. 13, no. 3, pp. 189192, 2001.

[15] C. Y. Liu, A. Datta, and Y. L. Wang, "Ordered anodic alumina nanochannels on focused-ion-beam-prepatterned aluminum surfaces," Applied Physics Letters, vol. 78, no. 1, article 120, 3 pages, 2001.

[16] G. H. Jeong, S. K. Lim, J. K. Park, D. Lee, B. K. Lee, and S. J. Suh, "Nano-pore arrays of anodic aluminum oxide fabricated using a Cr mask," in Proceedings of the 20th International Microprocesses and Nanotechnology Conference (MNC '07), pp. 192-193, Kyoto, Japan, November 2007.

[17] Y.-C. Ha and D.-Y. Jeong, "Fast fabrication of a high-aspectratio, self-ordered nanoporous alumina membrane by using high-field anodization," Journal of the Korean Physical Society, vol. 57, no. 61, pp. 1661-1666, 2010.

[18] L. Zaraska, G. D. Sulka, J. Szeremeta, and M. Jaskuła, "Porous anodic alumina formed by anodization of aluminum alloy (AA1050) and high purity aluminum," Electrochimica Acta, vol. 55, no. 14, pp. 4377-4386, 2010.

[19] I. Tsangaraki-Kaplanoglou, S. Theohari, T. Dimogerontakis, Y.M. Wang, H.-H. Kuo, and S. Kia, "Effect of alloy types on the anodizing process of aluminum," Surface and Coatings Technology, vol. 200, no. 8, pp. 2634-2641, 2006.

[20] D. Lo and R. A. Budiman, "Fabrication and characterization of porous anodic alumina films from impure aluminum foils," Journal of the Electrochemical Society, vol. 154, no. 1, pp. C60C66, 2007.

[21] J.-P. Dasquet, D. Caillard, E. Conforto, J.-P. Bonino, and R. Bes, "Investigation of the anodic oxide layer on 1050 and 2024T3 aluminum alloys by electron microscopy and electrochemical impedance spectroscopy," Thin Solid Films, vol. 371, no. 1, pp. 183-190, 2000.

[22] C. H. Voon, M. N. Derman, and U. Hashim, "Effect of manganese content on the fabrication of porous anodic alumina," Journal of Nanomaterials, vol. 2012, article 1, 2012.

[23] A. T. Shawaqfeh, Fabrication and characterization of novel anodic alumina membranes [Ph.D. thesis], Clarkson University, New York, NY, USA, 1997.

[24] N. Wang, W. Zhang, J. Xu et al., "Initial stage of pore formation process in anodic aluminum oxide template," Journal of Solid State Electrochemistry, vol. 14, no. 8, pp. 1377-1382, 2012.

[25] J. P. O'Sullivan and G. C. Wood, "Morphology and mechanism of formation of porous anodic films on aluminum," Proceedings of the Royal Society A, vol. 317, no. 1731, pp. 511-6, 1970. 
[26] O. Jessensky, F. Müller, and U. Gösele, "Self-organized formation of hexagonal pore structures in anodic alumina," Journal of the Electrochemical Society, vol. 145, no. 11, pp. 3735-3740, 1998.

[27] G. D. Sulka and W. J. Stepniowski, "Structural features of selforganized nanopore arrays formed by anodization of aluminum in oxalic acid at relatively high temperatures," Electrochimica Acta, vol. 54, no. 14, pp. 3683-3691, 2009.

[28] P. Chowdhury, K. Raghuvaran, M. Krishnan, H. C. Barshilia, and K. S. Rajam, "Effect of process parameters on growth rate and diameter of nano-porous alumina templates," Bulletin of Materials Science, vol. 34, no. 3, pp. 423-427, 2011.

[29] S.-K. Hwang, S.-H. Jeong, H.-Y. Hwang, O.-K. Lee, and K.H. Lee, "Fabrication of highly ordered pore array in anodic aluminum oxide," Korean Journal of Chemical Engineering, vol. 19, no. 3, pp. 467-473, 2002.

[30] T. Aerts, T. Dimogerontakis, I. de Graeve, J. Fransaer, and H. Terryn, "Influence of the anodizing temperature on the porosity and the mechanical properties of the porous anodic oxide film," Surface and Coatings Technology, vol. 201, no. 16-17, pp. 73107317, 2007.

[31] J. C. Ganley, K. L. Riechmann, E. G. Seebauer, and R. I. Masel, "Porous anodic alumina optimized as a catalyst support for microreactors," Journal of Catalysis, vol. 227, no. 1, pp. 26-32, 2004. 

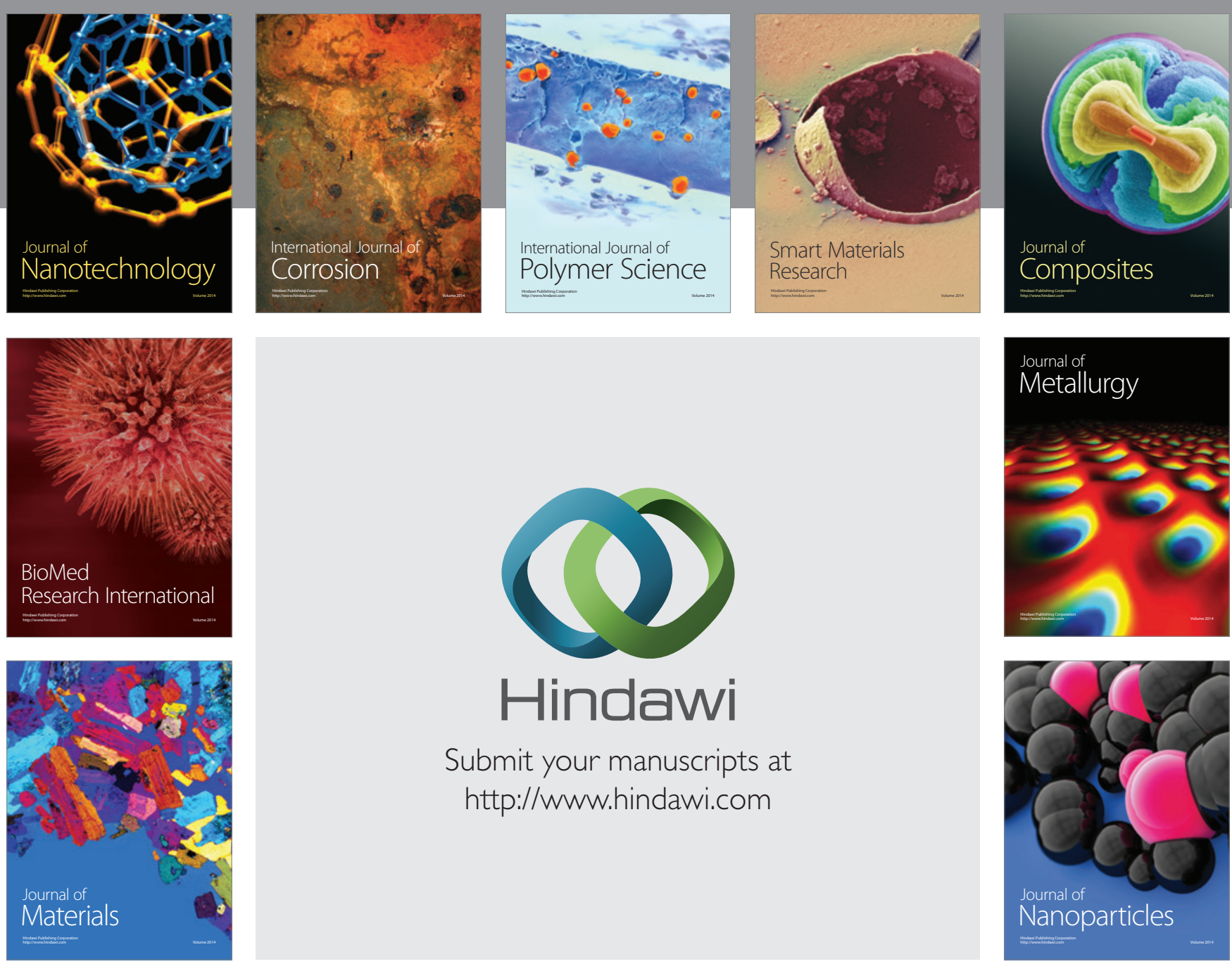

Submit your manuscripts at http://www.hindawi.com
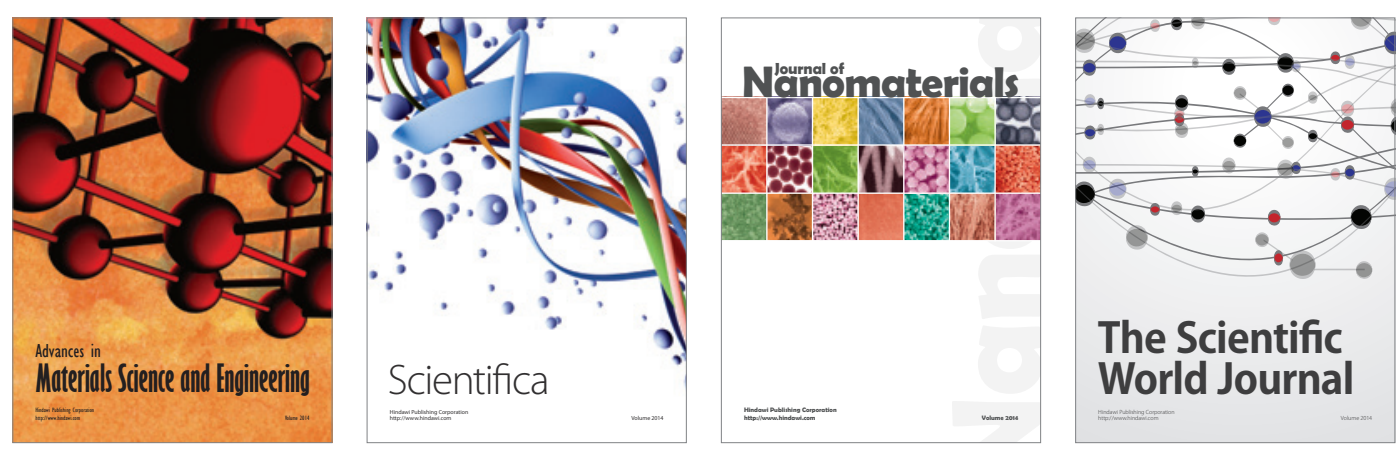

\section{The Scientific World Journal}
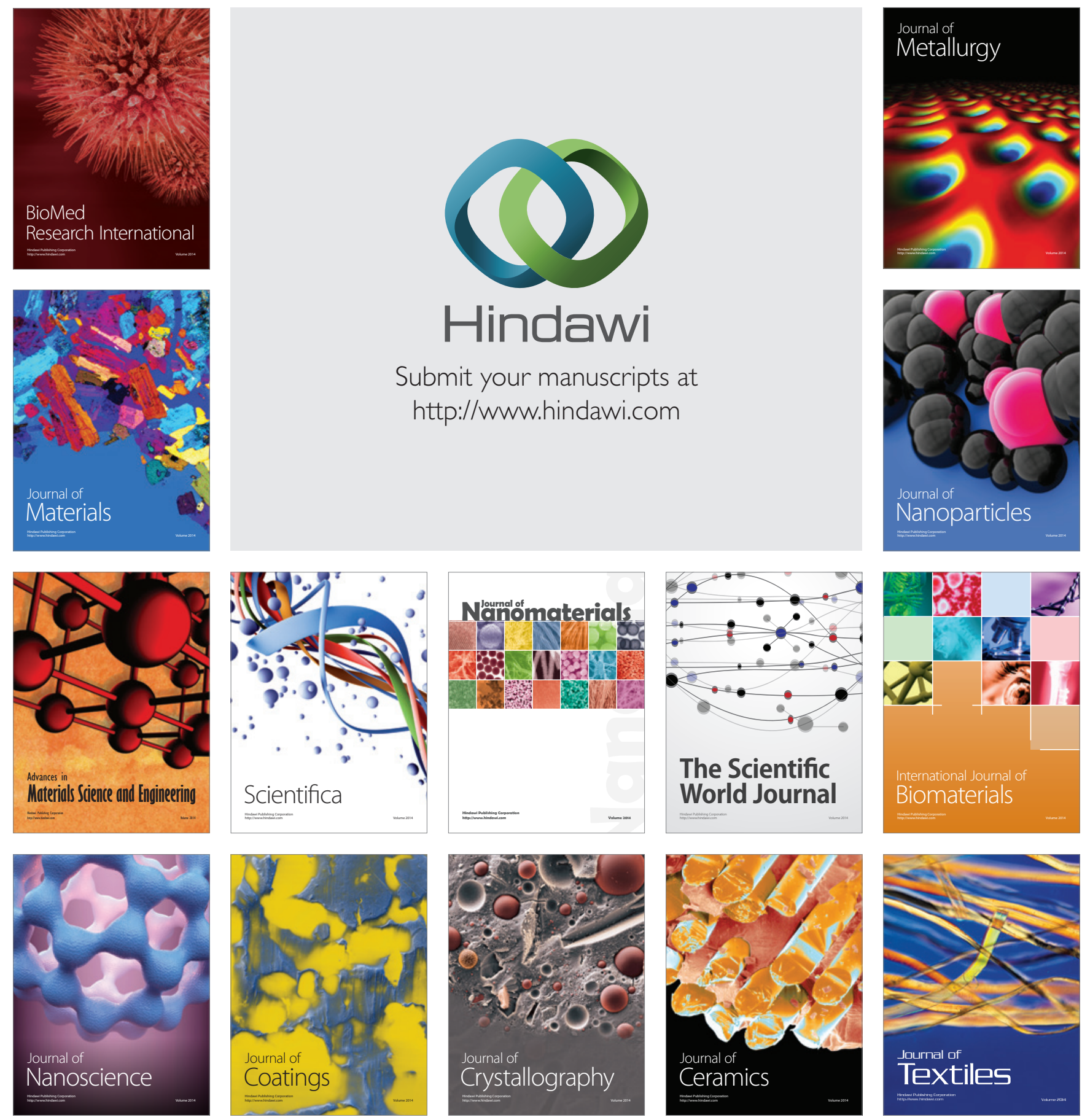